\title{
An Experimental Study of the POUM Hypothesis*
}

\author{
Daniele Checchi \\ (University of Milan) \\ daniele.checchi@unimi.it
}

\author{
Antonio Filippin \\ (University of Milan, EUI and IZA) \\ antonio.filippin@,iue.it
}

July 2003

\begin{abstract}
The "prospect of upward mobility" (POUM) hypothesis formalised by Benabou and Ok (2001a) finds explicit assumptions under which some individuals that are poorer than the average optimally choose to oppose redistribution policies. The underlying intuition is that these individuals rationally expect to be richer than average in the future. This result holds provided the mobility process is concave in expectations, redistribution policies are expected to last for a sufficiently long period and individuals are not too risk averse. This paper tests the POUM hypothesis by means of a within subjects experiment where the concavity of the mobility process, the degree of social mobility, the knowledge of personal income and the degree of inequality are used as treatments. Other determinants of the demand for redistribution, such as risk aversion and inequality aversion are (partially) controlled for via either the experiment design or the information collected during the experiment. We find that the POUM hypothesis holds under alternative specifications, even when we control for individual fixed effects.
\end{abstract}

Corresponding author:

Daniele Checchi

Facoltà di Scienze Politiche

Università degli Studi di Milano

via Conservatorio 7

20122 MILANO - Italy

tel. +39-02-503-21519(dir) 21501(secr) fax +39-02-503-21505

email daniele.checchi@unimi.it

\footnotetext{
* Financial support from MIUR-COFIN funds is gratefully acknowledged. We thank Roland Benabou for constructive comments that helped to improve the paper. We also thank Cecilia Garcia-Peñalosa, John Hey, Eliana La Ferrara, Michele Santoni and two anonymous referees for valuable suggestions. All the remaining errors are ours.
} 


\section{Theoretical Insights}

Benabou and Ok (2001a) have recently suggested a hypothesis to explain why a majority of poor do not fully expropriate the rich. They formally show that a rational individual with an income below the average who expects to achieve an income above the average in the near future will reduce her support for redistribution, once she takes into account the income gains she may obtain in the future. They indicate this situation as prospect of upward mobility (POUM) and provide several propositions that characterise the validity of the claim. ${ }^{1}$

The type of redistributive scheme they adopt is a standard one in political economy models and is based on proportional taxation with universal lump-sum redistribution, without dead-weight losses from tax collection or subsidisation. ${ }^{2}$ In such a context, the economic agent has to choose a tax rate $\tau_{t}$ in order to maximise the discounted flow of (expected) future income, where the net income accruing in each period is given by

$$
\hat{y}_{t}=y_{t}+\tau_{t}\left(\bar{y}_{t}-y_{t}\right)
$$

and where $\hat{y}_{t}$ indicates income net of taxation and $\bar{y}_{t}$ represents the average income in the population. ${ }^{3}$ This set-up can be simplified by neglecting income growth $\left(\bar{y}_{t}=\bar{y}, \forall t\right)$. When income is deterministic, the optimal choice rule, as long as inequality aversion does not matter, is zero redistribution $\left(\tau_{t}=0\right)$ when you are richer than average, and full redistribution $\left(\tau_{t}=100\right)$ when poorer than the average. When income becomes stochastic, additional elements interplay in shaping individual choices: the degree of risk aversion, the time length of validity of the tax rate to be selected and the skewness of future income distribution.

Under the assumptions of risk neutrality and deterministic transition functions, Benabou and Ok (2001a) obtain two main results:

1) the more concave (i.e. the more skewness-reducing) the transition function, the smaller will be the fraction of population with a below-average current income supporting redistribution (Theorem 1). ${ }^{4}$

\footnotetext{
1 Similarly, Ravallion and Loskin 2000 borrow the expression of "tunnel effect" to indicate that the attitude towards redistribution depends of expectations over future income trends: "We see that amongst people who expect welfare to fall, there is a very high support for restricting incomes of the rich, and the support is affected little by current level of living. By contrast, support for redistribution is lower than average among those who expect welfare to rise, and is sharply attenuated by higher current levels of living within this group." (p.97).

${ }^{2}$ Linear taxation schedules are discussed in Meltzer and Richards 1981.

${ }^{3}$ Notice that we have implicitly assumed that tax rate is expected to last for the future, thus excluding time consistency problems.

4 The analogy between transition function and progressive, balanced budget, redistributive schemes is developed in Benabou and Ok 2001b.
} 
2) the longer the period of validity for the chosen taxation, the smaller will be the fraction of population with a below-average current income supporting redistribution (Theorem 2).

When they consider stochastic transition functions, the concavity property is required in expectations over the following period(s). For discrete income values they also provide a characterisation of $3 \times 3$ monotone transition matrices assuring long-term, non-degenerate distributions, which are characterised by a strict majority of population voting for current redistribution that differs from the strict majority voting against future redistribution. Abandoning risk neutrality in favour of risk aversion under income uncertainty, the support for income redistribution increases, creating a trade-off between upward mobility and income insurance. ${ }^{5}$

Their paper provides theoretical insights into the analysis of the demand for redistribution, which has typically been analysed on empirical grounds using social surveys of the population attitude towards the role of government. Using a survey conducted in Russia in the mid 90's, Ravallion and Lokshin (2000) find that the support for the proposition "Should the government restrict the income of the rich?" declines not only with current socio-economic status (as proxied by current expenditure) but also with the expectation of future welfare improvements. Additional evidence is offered by Corneo and Grüner (2002) using a wider sample of 12 countries surveyed in 1992. ${ }^{6}$ In addition to the negative correlation between current status and support for redistribution (that they term "bomo aconomicus effect"), they show that individuals take into account societal values and expectation on relative social position (termed "social rivaly effect'). These last two factors have connections with the degree of mobility. In the first case, the authors find support for the argument initially put forward by Piketty (1995), according to which people are less favourable to redistribution if they believe that individual effort is the main determinant of one's social position. On the contrary, they will favour redistribution whenever family background is held to be the major determinant of income. As a consequence, individuals (or regions/countries) who experienced high degrees of mobility will oppose redistribution, whereas we will observe support for it in less immobile societies. The last factor, social rivalry, is expected to affect the opinions of middle income families: if a middle income person fears that redistribution will reduce her social distance from the poor, she might oppose it despite a positive income gain associated to redistribution. ${ }^{7}$

\footnotetext{
${ }^{5}$ In other words, the curvature of transition function and utility work in opposite directions.

${ }^{6}$ The crucial question they exploit says "Is it the responsibility of the government to reduce the differences in income between people with high incomes and those with low incomes?".

7 And conversely, a middle-income person with an income above the mean may support redistributive programs despite the associated capital loss if the reform reduces social distance with the elites. This is typical of educational expenditure: see Corneo and Grüner 2000.
} 
While the POUM idea makes reference to individual prospects of mobility, both Ravallion and Lokshin (2000) and Corneo and Grüner (2002) consider the perception of mobility experienced at community level, on the argument that individuals form their expectations through on observing what happens around them. However, the two concepts can be distinguished, as done by Alesina and LaFerrara (2002). The authors have ingeniously tested the determinants of preferences for redistribution conditioning on expected income mobility. Using data covering two decades of US citizens' samples, they study the determinants of preferences for redistribution, ${ }^{8}$ controlling for current income, past experience of mobility, local perception of general (aggregate) mobility and expected future income according to observed transition matrices. While some characteristics play a significant role (minorities, women and young people being more supportive), they rely on proxies to control for risk aversion (self-employment, past experience of unemployment) and altruism (helping others) finding positive and significant effects. They also control for present income, finding a negative impact on the support for redistribution. What is more relevant for our analysis is that they find a negative impact of the prospect of upward mobility, as measured either by subjective perceptions (by the answer to the question on whether the respondent believes that he and his family "have a good chance of improving their standard of living") or by objective measures (the local probability to go beyond mean income or the individual expected income conditional on current income). Finally they find a mixed effect of individual past experience of mobility (negative impact when measured by occupational prestige, positive impact when measured by years of education). Overall the findings of Alesina and LaFerrara (2002) do not contradict the POUM hypothesis: individuals who expect to achieve an above average income in the near future are less in favour of income redistribution, even if their current income falls below the average. Their results are robust against measured risk aversion and altruism, both factors pushing for more redistribution.

Previous literature suggests that it is almost impossible to provide a convincing test of the POUM hypothesis starting from empirical data, ${ }^{9}$ since the demand for redistribution is affected by too many factors: self-interest, risk aversion and individual history of mobility at individual level; altruism, inequality aversion, social rivalry and perception of aggregate mobility at social level. Last, but not least, the POUM hypothesis is obtained in a median voter context, where strategic voting by agents is not

\footnotetext{
8 The support for redistribution is measured by the answers to the following question: "Should the government reduce income differences between the rich and the poor, perhaps by raising the taxes of wealthy families or by giving income assistance to the poor?".

${ }_{9}^{9}$ Benabou and Ok (2001a) make use of empirically estimated transition matrices from PSID samples to show that under risk neutrality actual data allows for strict majority against redistribution, whereas even small amounts of risk aversion dominate mobility prospects.
} 
considered. Had an agent to consider her direct participation in a redistributive programme, a bargaining over the tax rate could be devised, and clear-cut results are difficult to obtain. Similarly, the empirical test proposed by Alesina and LaFerrara (2002) is based on a question of what a generic government should do, and does not concern individual willingness to participate in this redistribution.

For this reason we undertake a different route, trying to disentangle as many factors as we can in a lab experiment, getting as close as we can to the different assumptions introduced by Benabou and Ok. In this way we are able to isolate (and to control for) the following factors:

* current income position (and therefore self-interest)

$*$ individual prospect of mobility (under rational expectations ${ }^{10}$ )

* risk aversion

* fairness (or inequality aversion)

* length of time horizon

$*$ imperfect rationality.

The main limit of our strategy is that we neglect the political game. In our experiment we ask participants about their preferred tax rate, irrespective of the actual implementation of the chosen rate. Each participant chose a preferred rate in isolation as if she were the pivotal agent. ${ }^{11}$ In this way we neglect the issue of preference aggregation, and concentrate on individual attitude towards redistribution. These limits are shared by the previous literature: social surveys ask individuals their opinion about redistributing income, not whether they purposely operate to introduce redistributive schemes (like voting for parties promising redistributive actions). A final point is worth discussing: social surveys are based on order preferences measuring the intensity of the internally perceived desire for redistribution; lab experiments provide monetary equivalent of the same desire. We believe monetary equivalent to be a more precise and more trustworthy measure of the intensity of the demand for redistribution. This does not imply that our results actually correspond to behaviour in the real world, where agents do not have direct control over their income nor over fiscal redistribution; in addition, emotions, political ideologies and other factors affect beyond what we can control for. Nevertheless our results are still suggestive of the economic determinants of the attitude towards redistribution.

\footnotetext{
${ }^{10}$ As it will be made clear in the sequel, we provided the participants with a device allowing them to compute their expected income in the future for any given transition matrix they were facing.

${ }^{11}$ Since we provided participants with information about the income distribution, in principle each participant would have been able to assess the likelihood of choice of her preferred rate. But actual gains were obtained using the chosen rate, thus implicitly assuring its implementation.
} 


\section{The Experiment}

\section{1 - Experimental Procedure}

The experiment was run in January 2003, using the zTree software. ${ }^{12}$ We recruited subjects from undergraduate courses at the University of Milan. All the subjects were inexperienced. Participants were randomly assigned subjects' numbers and seats. Subjects were told that their physical identity was not associated to their choices during the experiment, the subjects' numbers being their personal identification. They were given written instructions that were also read aloud by the experimenters, stressing that the amount they earned was a function of their decisions. In addition, instructions were also displayed on the screen at the beginning of each treatment (see Appendix A).

After questions were raised, a quiz was run to test their comprehension of the basic redistribution mechanism outlined in section 1. Then, two treatments were performed. The first asked to choose a tax rate knowing one's income level and the average income. During the second only the set of three income levels and the average income were known. In both cases, the subjects' earnings corresponded in every trial to the level of their final income, net of the chosen tax rate. ${ }^{13}$ Another quiz followed, testing subjects' comprehension of a transition matrix. The answers to the first two treatments are used in the sequel to build proxies for fairness and risk aversion, and then used in regression analysis as controls for the actual comprehension of the experiment game.

At this point, six treatments characterized by a common structure but different parameter sets were performed. Subjects, knowing their personal level of initial income, had to choose their preferred tax rate to be applied to a sequence of unknown future incomes. Every time participants had to choose a tax rate knowing the initial income only. They were supported by both a transition matrix and a "simulator." The latter, without involving real money, allowed the computation of the sequence of expected incomes implied by the proposed transition matrix, net of three different fictitious tax rates chosen by the participant. The simulator was presented as a radio-line along which subjects could move a pointer. Only the extremes of the interval $[0,100]$ were displayed, while the radio-line was not scaled in between (see Appendix B for the instructions submitted to the subjects). After the output of the simulator was shown, participants had to choose the "true" tax rate, i.e. the tax rate that, once applied

\footnotetext{
12 The zTree software has been developed at the University of Zurich, Institute for the Empirical Research in Economics.

13 Cowell and Schokkaert 2001 claim that it is unclear that rewards to participants are necessary in the context of social judgements. However, we decided to reward subjects even in this treatment to mimic the fact that fairness is costly.
} 
to the sequence of future incomes, determined their earnings. In more detail, in every round each subject earned the realization of her income, unknown when the tax rate had been chosen, net of the chosen tax rate.

At the end of the experiment a questionnaire was proposed, reminding participants that their physical identity was not associated to their choices and their answers during the experiment. Questions concerned academic as well as personal information. ${ }^{14}$ The answers are used as controls in the regressions we show in section 3. Below (section 2.3) we present some descriptive statistics of the pool of subjects.

Overall 95 subjects participated in the experiment, which was run in three sessions. The sessions lasted approximately 75 minutes each, and were respectively composed of 28, 30 and 37 subjects. "Points" were the currency used during the experiment, with an exchange rate of 300 points $=1$ euro. Final earnings ranged between 8.2 and 10.9 Euro, and were determined by the sum of all the points collected during the experiment, i.e. the sum along periods of the points corresponding to each subject's realized income net of taxation.

One aspect of our experimental procedure needs to be stressed. All the treatments were proposed within each of the three sessions of the experiment. Hence, all the subjects played facing the whole set of parameters. This procedure implies potential carry-over effects from one parameter set to the others, as well as confounding factors arising because of framing, learning and fatigue. However, such effects can be controlled for using an econometric approach to the analysis of the data. The main advantage of this approach is that it allows the control for any observable and/or unobservable individual characteristics that might have affected the choices of the participants during the experiment, as explained in more detail in section 3. This outcome cannot be obtained under a between-subject experiment where individual characteristics might idiosyncratically affect results across treatments without the possibility of being controlled for. For this reason we maintain that a within-subject procedure better fits the requirements for estimating the demand for redistribution than a betweensubject procedure would do.

\footnotetext{
${ }^{14} \mathrm{We}$ did not include in the questionnaire verbal questions addressed to find out the attitudes of individuals towards the POUM. Although this would have allowed us to check the numerical answers obtained in the experiment, as Amiel and Cowell 1999 suggest, we did not want to overload the subjects since the design of the experiment required already a large amount of time.
} 


\section{2 - Experimental Design}

Given our aim of investigating the demand for redistribution in the lab, with a specific emphasis on the role of the POUM hypothesis, we have purposely excluded any interaction between subjects in the course of the experiment. Each participant decided on her own a tax rate to be applied to her income only, which in turn was not affected by the tax rates chosen by the other participants. Each simply chose her preferred tax rate given a predetermined and constant distribution of incomes within an imaginary population, which nobody else in the lab belonged to. Roughly speaking, every participant belonged to a different population and there were as many populations as participants.

The initial treatments were proposed to collect some information to be used to derive some (admittedly rough) proxies for fairness and risk aversion, two factors that the literature indicates as important determinants of the demand for redistribution. Treatment 1 dealt with fairness. Subjects chose a tax rate to be applied for one period to their known level of income. This choice is repeated three times, and all subjects were both rich and poor at least once. In this case the subjects had all the necessary information to choose the tax rate maximizing their net earnings known with certainty. Calling $\tau$ the chosen tax rate in treatment 1 , we interpret $\tau$ (and indicate this variable as FAIR1) as a proxy for fairness of the individual when rich (i.e. with an income above the average), since a selfish optimal choice would suggest $\tau=0$. When the individual got an income below average, the optimal choice would have required $\tau=100$, leading to an egalitarian redistribution of incomes. If the participants held the opinion that full expropriation was excessive, they were expressing a different notion of fairness, where a certain degree of income inequality was held reasonable, or even necessary. Thus we construct a second measure for fairness as $(100-\tau)$ (and indicate this variable as FAIR2) when the individual obtained an income below the average in Treatment 1 . These two measures are positively correlated (0.378) between them. ${ }^{15}$ A shortcoming of $\tau$ is that it may be confounded by an incomplete comprehension of the game, thus preventing subjects from fully exploiting their opportunities. This possibility is even more likely when we consider that fairness in everyday life means transferring some money to the poor, whereas during the experiment it meant leaving money to the experimenters (given the absence of interaction among the players). However, the effect of an incomplete comprehension of the game can be separately controlled for by including the number of wrong answers provided during the first of the two quizzes that have been proposed.

\footnotetext{
15 Among the determinants of social preferences analysed by Fong 2001, only altruism can contribute to explain FAIR1 and FAIR2. In fact, the setting of the experiment, and in particular the lack of interaction among subjects, prevents equity and reciprocity from playing any role.
} 
Treatment 2 was designed to compute a proxy for risk aversion. Subjects chose a tax rate to be applied to an unknown level of income. They just knew the possible levels of income, the average income, and the relative probability of each occurrence. They chose under two different sets of income levels. Given the rules of the game and the equal probability of each income level, a risk lover should have chosen $\tau=0$, while a risk averter should have chosen $\tau=100 .{ }^{16}$ Given that 94 out of 95 subjects chose at least once a tax rate between these two extremes, we thought it would be implausible concluding that these subjects were risk neutral, and we decided to keep the highest tax rate chosen in the two versions of treatment 2 as a proxy for risk aversion (and indicate this variable as RISKAV). ${ }^{17}$ There is evidence of a limited degree of risk aversion and inequality aversion, but also excessive equality seems to be rejected by our subjects. Looking at the distribution of our proxies for fairness and risk aversion, there is evidence of a limited degree of risk aversion and inequality aversion, but excessive equality also seems to be rejected by our subjects. In addition, the proxy for risk aversion is not correlated with the proxies for fairness.

The core of the experiment analysed the demand for redistribution under uncertain future incomes, obtained applying a known transition matrix to a known initial income. Six different parameter sets, summarized in Table 1 (rows 3-8), were used in each session. To reduce the role of confounding factors, all the treatments differed from one another by a change in just one parameter.

Table 1. List of treatments

\begin{tabular}{ll}
\hline $\mathbf{1}$ & Tax on known income (proxy for fairness) \\
$\mathbf{2}$ & Tax on unknown income (proxy for risk aversion) \\
$\mathbf{3}$ & Transition matrix: low mobility, high income inequality \\
$\mathbf{4}$ & Transition matrix: high mobility, high income inequality \\
$\mathbf{5}$ & Transition matrix: POUM, high income inequality \\
$\mathbf{6}$ & Transition matrix: low mobility, low income inequality \\
$\mathbf{7}$ & Transition matrix: high mobility, low income inequality \\
$\mathbf{8}$ & Transition matrix: POUM, low income inequality \\
\hline
\end{tabular}

Within each of these six treatments, participants were initially assigned an initial income, randomly drawn from a uniform distribution. Knowing this initial income, they had the opportunity to simulate what they could expect to get under three fictitious tax rates. After experimenting with these simulations, they had to choose a tax rate to be applied to the unknown income in the following period. The income levels to be taxed were finally assigned conditional on the initial income and on the

\footnotetext{
16 There is a debate in the literature about whether people are really expected-utility maximizers, and how small-stake gambles in the laboratory, like in Treatment 2 in our experiment, relate with behaviour in the real world (see Rabin 2000 and a response by Palacio-Huerta, Serrano and Volij 2001).

17 We also tried with an average between the two, finding results that are slightly less significant.
} 
probabilities contained in the transition matrix. The following information was displayed at the end of the round: initial income, chosen tax rate, net and gross income obtained in the following period. This procedure was repeated three times within each treatment: the second time a sequence of three income levels was randomly assigned after the choice of the tax rate, while in the third time the chosen tax rate was applied to a sequence of five income levels randomly assigned. ${ }^{18}$ The order of these treatments was changed in the three sessions. ${ }^{19}$ Three permutations out of the thousands available are clearly insufficient to control for the potential role of carry-over effects, framing, learning and fatigue. Nevertheless, such problems can be dealt with when performing an econometric analysis of the results (see section 3).

The six parameter sets consisted of three different transition matrices under two different sets of income levels. On the one hand, two different sets of income levels were used to test whether a different degree of income inequality affected the demand for redistribution. The sets of income levels were $(30 ; 40 ; 65)$ and $(20 ; 40 ; 75)$, respectively. Given that the realizations of initial income were drawn from a uniform distribution, it follows that the average income was always the same, i.e. equal to 45 points in all periods of every treatment. On the other hand, three different transition matrices were aimed at testing two important effects:

i. how social mobility affects the demand for redistribution

ii. the POUM hypothesis.

These two effects are related but they can be tested separately. In fact, looking at the transition matrices that have been proposed during the experiment, we see that

- matrix $\mathbf{A}$, used as a benchmark, is characterized by a low income mobility and absence of POUM effect: the expected income for the following period of subjects with a median income (40) is equal to 42 in the low inequality case and to 41 in the high inequality case, i.e. lower than the average income (45) in both cases.

- matrix $\mathbf{B}$ also, although characterized by higher income mobility, ${ }^{20}$ does not satisfy the requirement of the POUM hypothesis: expected future income for the median current income is again below the average income, being either 41 (low inequality) or 39 (high inequality).

\footnotetext{
18 The sequences of future income levels were obtained by iterated randomisation based on the probabilities contained in the transition matrix.

19 The sequence of treatments in the three sessions was as follows:

$\begin{array}{ll}\text { Session 1: } & 12345876 \\ \text { Session 2: } & 21854367 \\ \text { Session 3: } & 21763458\end{array}$

Session 3: $\quad 21763458$

20 The three matrices can be ordered in terms of mobility. If we take the second eigenvalue as a measure of relative immobility, the compute values are the following: $\mathbf{A}=0.764 ; \mathbf{B}=0.564 ; \mathbf{C}=0.464$. See also the speed of mean-regression from figure 1.
} 
- finally, matrix $\mathbf{C}$ implies the Prospect of Upward Mobility hypothesis, the expected income for the median current income being above the average income (47 in the low inequality case, 48 in the high inequality case). When looking at figure 1 reporting the expected incomes for future period, we notice that middle income still converge to the mean but from above, and not from below as in the no-POUM transition matrices. ${ }^{21}$

In all cases, note that the different transition matrices share the feature that they leave the distribution of incomes unchanged. 22

Matrix A

\begin{tabular}{c|c|c|c|}
\hline From $\backslash$ to & \multicolumn{1}{c}{ LOW } & \multicolumn{1}{c}{ MED. } & HIGH \\
LOW & 0.7 & 0.3 & 0 \\
\cline { 2 - 4 } MED. & 0.3 & 0.5 & 0.2 \\
\cline { 2 - 4 } HIGH & 0 & 0.2 & 0.8 \\
\cline { 2 - 4 } & & &
\end{tabular}

Matrix B

\begin{tabular}{c|c|c|c|}
\hline From $\backslash$ to & \multicolumn{1}{c}{ LOW } & \multicolumn{1}{l}{ MED. } & HIGH \\
LOW & 0.5 & 0.4 & 0.1 \\
\cline { 2 - 4 } MED. & 0.4 & 0.4 & 0.2 \\
\cline { 2 - 4 } HIGH & 0.1 & 0.2 & 0.7 \\
\cline { 2 - 4 } & & &
\end{tabular}

Matrix C

\begin{tabular}{c|c|c|c|}
\hline From $\backslash$ to & \multicolumn{1}{c}{ LOW } & \multicolumn{1}{c}{ MED. } & HIGH \\
LOW & 0.6 & 0.3 & 0.1 \\
\cline { 2 - 4 } MED. & 0.3 & 0.3 & 0.4 \\
\cline { 2 - 4 } HIGH & 0.1 & 0.4 & 0.5 \\
\hline
\end{tabular}

The subjects were confronted with all three matrices in different order (see footnote 14), and they were told that the tax they were to choose would last one, three or five periods. Our test of the POUM hypothesis investigates whether, after controlling for all potential observables referred to the subjects and the experiment frame, the tax rate chosen when confronted with matrix $\mathbf{C}$ was systematically lower than the rates chosen under matrices $\mathbf{A}$ or $\mathbf{B}$.

\footnotetext{
21 This is equivalent to figure 2 in Benabou and Ok 2001a.

${ }^{22}$ From the matrices A and B, i.e. when the POUM does not hold, it could be possible in principle to infer something about the risk aversion and the fairness of the subjects. In fact, being the expected income of the non-rich subjects always below the mean, a choice of a tax rate lower than $100 \%$ would signal either risk loving or fairness to the rich. Unfortunately, it is not possible to distinguish between the two. Moreover, the correlation between fraction of times in which a subject has chosen a tax rates below 100\% when it would have been rational to do so, and any of our proxies of fairness and risk aversion is very low.
} 
Figure 1 - Expected incomes according to different transition matrices
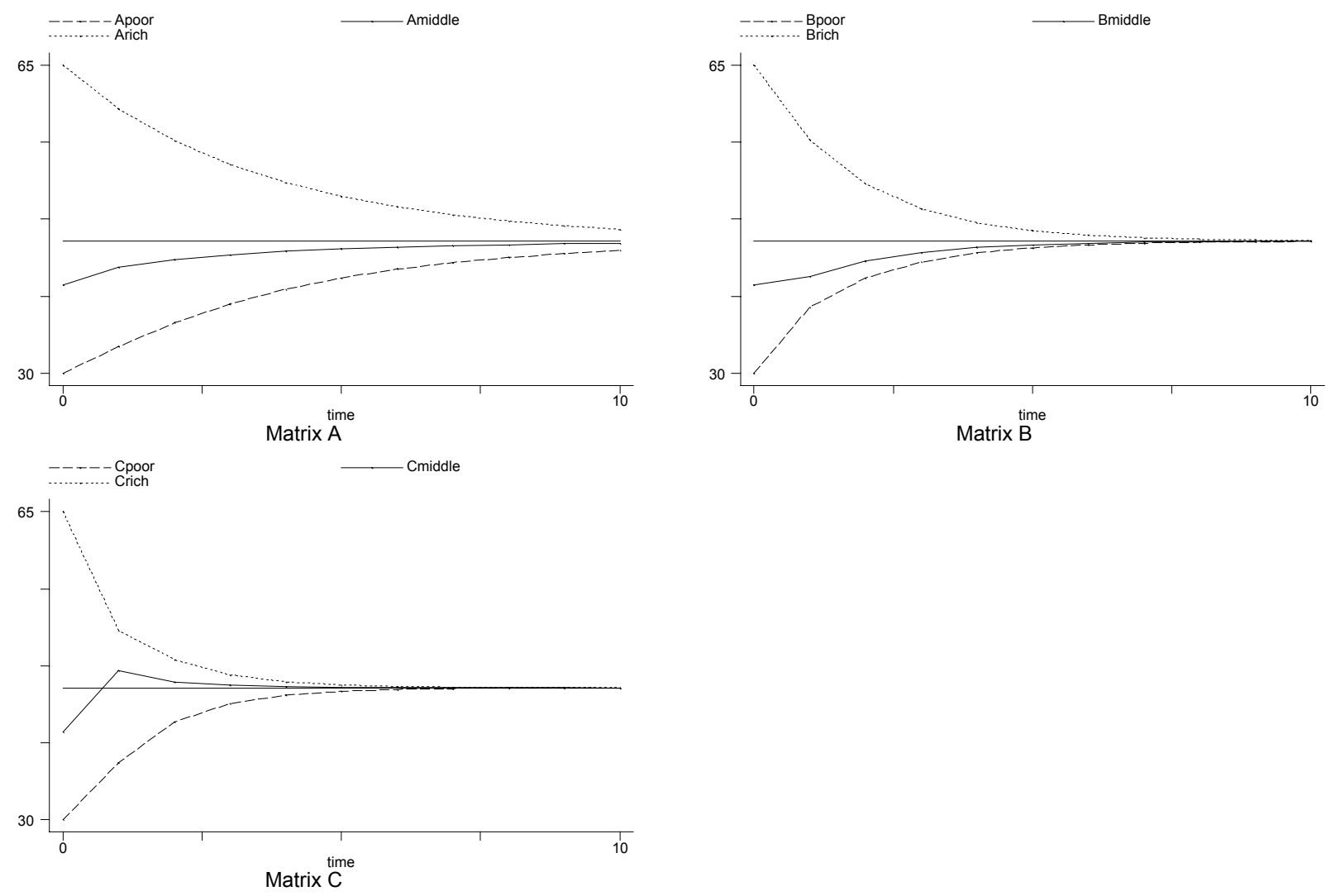

\section{3 - Sample description}

From the information collected by means of the final questionnaire, it turns out males were over represented in our sample $(60 \%$ vs. $40 \%)$, and the average age of the pool was 23 years. Other descriptive statistics are reported in table 2. Most of the participants $(89 \%)$ came from the School of Political Sciences, and were enrolled in the second year of their degree program. The final mark at the exit of secondary school has been chosen as a proxy for a student's ability, after rescaling the variable in the range $[0,1]$. Two thirds of the sample came from high schools (licei) and one fourth from technical schools (istituti tecnici).

Two specific questions concerned the political and religious orientation, given the importance that these two variables are supposed to play in determining the demand for redistribution. An ordered scale from 0 to 5 was used to ask subjects their political orientation $(0=\mathrm{left} ; 5=$ right), without any label on each possible choice. $63 \%$ of the subjects reported themselves as being centre-left, i.e. they chose a value from 0 to 2 , while $37 \%$ as being centre-right. The average was 2.09 while the median choice was 2. With respect to religion, the subjects were asked to locate themselves under three alternatives: 
"believer and churchgoer", "believer but not churchgoer", "non believer". The proportion of the last occurrence was around one third (see table 3).

Table 2 - Descriptive statistics of the subjects - 95 subjects

\begin{tabular}{l|cccc} 
Variable & mean & st.dev. & $\min$ & $\max$ \\
\hline gender & 0.40 & 0.49 & 0 & 1 \\
age & 23.16 & 4.07 & 19 & 49 \\
year of enrolment & 1.95 & 2.28 & 0 & 10 \\
ability & 0.41 & 0.29 & 0 & 1 \\
errors 1st quiz & 7.12 & 5.24 & 0 & 19 \\
errors 2nd quiz & 0.69 & 1.81 & 0 & 8 \\
\hline
\end{tabular}

Table 3 - Political and religious orientation of the subjects - 95 subjects - self-assessment

\begin{tabular}{l|ccc|c} 
& $\begin{array}{c}\text { believer and } \\
\text { churchgoer }\end{array}$ & $\begin{array}{c}\text { believer, not } \\
\text { churchgoer }\end{array}$ & not believer & Total \\
\hline left-wing & 2 & 3 & 11 & 16 \\
left-centre & 5 & 10 & 10 & 25 \\
centre-left & 5 & 9 & 5 & 19 \\
centre-right & 4 & 8 & 2 & 14 \\
right-centre & 3 & 7 & 1 & 11 \\
right-wing & 2 & 5 & 3 & 10 \\
\hline Total & 21 & 42 & 32 & 95
\end{tabular}

From the quizzes proposed before the core of the experiment, it is possible to infer that subjects had, on average, an imperfect comprehension of the redistribution mechanism, given that the average number of wrong answers was about 7 out of 21 . At first sight, such a result points towards an insufficient comprehension of the basic mechanism. However, it should be taken into account that the problems to be solved within the quiz were more difficult than the problem of choosing a tax rate starting from a given level of income, also because in the latter case a simulator was available for a limited number of trials. ${ }^{23}$ On the other hand, the comprehension of the transition matrix was very good, with on average less than 1 mistake out of 8 answers.

\section{Results}

Our subjects reacted to the different prospect of mobility by adjusting the chosen tax rate. Since each subject was asked to choose a tax rate confronting each transition matrix twice (under reduced and enlarged income variability), under three different time horizons (one, three and five periods), 18 choices are available for each subject, leading to 1710 observations for the "optimal" tax rate. The average tax rate was 46.85 , with a median value of 45 and a standard deviation of 36.6. First and third quartiles were 10 and 80 respectively. There is therefore sufficient variability in the data to explore the

\footnotetext{
${ }^{23}$ Given three different tax rates, in the first quiz subjects had to indicate, for each of three different levels of income:

a) whether a tax or a subsidy emerged

b) the amount of the tax or the subsidy

c) how much the final income (net of taxation) was.
} 
potential contribution of different factors. When we look at table 4 we notice that the support for redistribution declined with the time length validity of the choice and with the degree of social mobility. Prima facie, the existence of prospects of upward mobility seems to reduce the support for redistribution, and the lengthening of the time horizon works in the same directions. Both results are in line with the predictions of the model proposed by Benabou and Ok (2001a), although the relation is not monotonic when the POUM holds. Since many other factors can confound these results, we resort to multivariate analysis in order to control for different sources of heterogeneity.

Table 4 - Conditional means of the preferred rate -1710 choices by 95 subjects

\begin{tabular}{l|ccc} 
matrix/period(s) & 1 & 3 & 5 \\
\hline Matrix A & 53.68 & 51.29 & 47.63 \\
Matrix B & 51.16 & 47.48 & 45.30 \\
Matrix C (POUM) & 47.62 & 37.84 & 39.70
\end{tabular}

In table 5 we have estimated a linear model to predict the preferred tax rates by our subjects. The table reports ordinary least square projections, with heteroskedastic robust standard errors estimates. ${ }^{24}$ In column 1 we start with the simplest version, accounting for (self reported) personal information, the initial level of income and our proxies for fairness and risk aversion. Contrary to Alesina and LaFerrara (2002) we find that women were less supportive of redistribution, although the coefficient is not significant at $95 \%$ confidence level, while similarly to them young people were more willing to redistribute. Religious attitudes do not enter significantly in our results, while political attitude does play a role: right-wing oriented individuals were less in favour of redistribution. ${ }^{25} \mathrm{~A}$ similar attitude is found with respect to individual ability: other things constant, the subjects that experienced greater success in schooling relied less on taxation. We also control for the correct understanding of the game by including the number of errors incurred at the beginning of the experiment. The errors in the $1^{\text {st }}$ quiz indicate the imperfect understanding of the principle of redistribution, and constantly induced an excess of redistribution: the subject with the maximum of errors (19 over 21) on average should have chosen 7.22 percent points of tax rate in excess of an identical person committing no mistakes. The errors in the $2^{\text {nd }}$ quiz indicate the imperfect understanding of a transition matrix: even if less frequent (the average is 0.7 error per individual), these errors induced less redistribution. Our measures for fairness work in the expected direction: inequality aversion when rich (FAIR1) induced more redistribution (even though of limited amount) ${ }^{26}$ whereas equality aversion when poor (FAIR2) reduced

\footnotetext{
${ }^{24}$ We have also estimated weighed least square, using the inverse of errors as weights, but the results are substantially unaltered. Available from the authors.

${ }^{25}$ Constant, Year of enrolment, Secondary school type and Faculty attended are always included as maintained controls.

${ }^{26}$ Given a sample mean for FAIR1 of 4.0, the additional redistribution induced by this variable is in the order of 1.5 percentage points.
} 
the preferred taxation. ${ }^{27}$ Our proxy for risk aversion exerted a stronger effect: given a sample mean of 52.1 for RISKAV, we find an additional redistribution induced by this variable of 2.6 percent points. In column 1 we also control for some conditions potentially affecting the choice, finding that assigned initial income strongly affected the preferred rate. Despite the fact that subjects were informed that subsequent incomes were randomly obtained through the mobility matrices applied to their initial income, they seemed to place strong emphasis on their starting conditions: when initially rich, they chose a sharply lower taxation than when initially poor. This effect is robust against all possible specifications. On the contrary, the extent of initial dispersion did not exert any role, but this does not come as a surprise, since we are already controlling for risk aversion. Without further controls, we find that the presence of matrix $\mathbf{C}$ (characterised by the prospect of upward mobility - see section 2) induced a reduction of 9.15 percent points in the preferred tax rate. This effect is robust against all successive specifications. It is worth noting that this effect is independent of greater mobility: in fact, matrix $\mathbf{B}$ is characterised by higher mobility than matrix $\mathbf{A}$ (the excluded case), but its presence was not associated with a significantly lower redistribution (as conditional means of table 4 would have erroneously suggested).

Column 2 decomposes the POUM effect by interacting it with the type of initial income, and finds that the POUM effect was much more pronounced for individuals that were below (but close to) average income, while there was no effect above the average. Note that these coefficients do not mean that the tax rate chosen by middle-income receivers is lower than the tax chosen by the low-income receivers, because the effect of the initial income must also be taken into account when predicting the optimal demand for redistribution. We also wanted to test whether past experience of mobility (during the course of the experiment) could have affected current choices. Therefore, for each subject we construct a moving dispersion measure over the incomes obtained during previous treatments. Our expectation is that, conditional on perfect partialling out of risk aversion (given the existence of a specific control for it), the volatility experienced by a subject should not affect the optimal choice of redistribution. However, despite the increased significance of the RISKAV coefficient, the experienced volatility bears a positive and significant sign, indicating that our proxy for risk aversion is not perfectly capturing the underlying phenomenon. ${ }^{28}$ In fact, when individual effects are introduced in column 3 to capture all the individual characteristics (including risk aversion), the size and the magnitude of this coefficient changes sharply. Column 2 also adds further controls related to the framing of the experiment: the order in which the treatment appeared, the length of the period of validity of the tax rate alone and

\footnotetext{
${ }^{27}$ Given a sample mean for FAIR2 of 24.4 , the additional redistribution induced by this variable is in the order of 1.7 percentage points.

${ }^{28}$ We also counted the number of upward or downward transitions as an alternative measure of individual mobility, without finding statistically significant effects.
} 
interacted with the occurrence of matrix $\mathbf{C}$ types. In more details, the number of periods during which the chosen tax rate was effective influenced the preferred tax rate. In line with the model proposed by Benabou and Ok (2001a), the longer the horizon the lower the taxation. However, this effect is not significantly different across matrices, meaning that the same reduction in the preferred tax rate happens regardless of the POUM hypothesis being satisfied or not. The dummies for the order in which treatment appeared turn out not statistically significant, meaning that framing, learning and fatigue did not produce a recognizable pattern in the data. It is worth noting that the changes in the magnitude or in the significance of some coefficients already included in column 1 (e.g. FAIR2) are due to the decomposition of the POUM matrix. In fact, adding only the framing variables to the regression shown in column 1 does not produce significant changes. Despite the additional controls, the POUM effect keeps on holding and the size and the significance of all the coefficients do not vary.

Finally, our strongest check is given by including individual fixed effects in column 3. Even in this case we find that initial income and the type of transition matrix are the main determinants of the extent of preferred redistribution. Other things being constant (and in this specification we are controlling for unobservables as well), the presence of a $\mathbf{C}$-type transition matrix, characterised by prospect of upward mobility, induced a strong reduction in preferred taxation for middle income subjects (in the order of 25 percent points). Stronger mobility per se (captured by B-type transition matrices) did not induce reduction of redistribution. 
Table 5 - Determinants of preferred tax rates -95 subjects

(ols robust standard errors $-\mathrm{t}$-statistics in parentheses with $\mathrm{p}<0.05=*, \mathrm{p}<0.01=* *$ )

\begin{tabular}{|c|c|c|c|}
\hline Model : & 1 & 2 & 3 \\
\hline \# obs : & 1710 & 1710 & 1710 \\
\hline \multicolumn{4}{|c|}{----------------------------------------------} \\
\hline \multicolumn{4}{|c|}{$\begin{array}{lll}\text { error } 1 & 0.38 * * & 0.37 * *\end{array}$} \\
\hline \multirow{2}{*}{\multicolumn{4}{|c|}{$\begin{array}{l}\text { gender } \\
(1=\text { female) }\end{array}$}} \\
\hline & & & \\
\hline \multirow[t]{2}{*}{ age } & $-0.53 \star \star$ & $-0.53 \star \star$ & \\
\hline & $(-2.96)$ & $(-2.95)$ & \\
\hline polit. & $-1 \cdot 35 \star \star$ & $-1 \cdot 32 \star \star$ & \\
\hline attitude & $(-2.69)$ & $(-2.66)$ & \\
\hline relig. & 0.65 & 0.72 & \\
\hline attitude & $(0.62)$ & $(0.71)$ & \\
\hline \multirow[t]{3}{*}{ talent } & $-8.37 * \star$ & $-9.04 * \star$ & \\
\hline & $(-3.57)$ & $(-3.89)$ & \\
\hline & $(2.71)$ & $(2.70)$ & \\
\hline \multirow{2}{*}{ error2 } & $-2.09 * \star$ & $-2.08 * \star$ & \\
\hline & $(-4.84)$ & $(-4.80)$ & \\
\hline \multirow[t]{2}{*}{ fair1 } & $0.38 * \star$ & $0.33 * \star$ & \\
\hline & $(6.67)$ & $(5.64)$ & \\
\hline \multirow[t]{2}{*}{ fair2 } & $-0.07 \star \star$ & -0.036 & \\
\hline & $(-2.58)$ & $(-1 \cdot 36)$ & \\
\hline \multirow[t]{2}{*}{ riskav } & 0.05 & $0.053 *$ & \\
\hline & $(1.85)$ & $(2.10)$ & \\
\hline \multirow{2}{*}{ Matrix B } & -1.01 & -0.54 & -0.10 \\
\hline & $(-0.66)$ & $(-0.33)$ & $(-0.06)$ \\
\hline $\begin{array}{l}\text { Matrix C } \\
\text { (poum) }\end{array}$ & $\begin{array}{l}-9.60 * \star \\
(-5.96)\end{array}$ & & \\
\hline \multirow{2}{*}{\multicolumn{2}{|c|}{$\begin{array}{l}\text { Matrix } \mathbf{C} \times \\
\text { low income }\end{array}$}} & $-7.94 * \star$ & $-6.89 * \star$ \\
\hline & & $(-3.14)$ & $(-2.33)$ \\
\hline \multicolumn{2}{|l|}{$\begin{array}{l}\text { Matrix } \mathbf{C} \times \\
\text { middl.incom }\end{array}$} & $\begin{array}{l}-24.43 \star \star \\
(-7.76)\end{array}$ & $\begin{array}{l}-25.41 \star \star \\
(-8.31)\end{array}$ \\
\hline \multirow{2}{*}{\multicolumn{2}{|c|}{$\begin{array}{l}\text { Matrix } \mathbf{C} \times \\
\text { High income }\end{array}$}} & 0.25 & -2.09 \\
\hline & & $(0.08)$ & $(0.66)$ \\
\hline \multirow{2}{*}{\multicolumn{2}{|c|}{ Length 3 pr }} & $-3.50 *$ & -2.70 \\
\hline & & $(-1.85)$ & $(-1.47)$ \\
\hline \multirow{2}{*}{\multicolumn{2}{|c|}{ Length 5 pr }} & $-6.07 \star \star$ & $-5.18 * \star$ \\
\hline & & $(-3.13)$ & $(-2.73)$ \\
\hline initial & $-1.37 \star \star$ & $-1.40 * \star$ & $-1 \cdot 30 * \star$ \\
\hline income & $(-33.14)$ & $(-32.84)$ & $(-34.79)$ \\
\hline init.income & -1.42 & -2.39 & -2.10 \\
\hline dispersion & $(-1.09)$ & $(-1.49)$ & $(-1.34)$ \\
\hline \multirow{2}{*}{\multicolumn{2}{|c|}{$\begin{array}{l}\text { experienced } \\
\text { volatility }\end{array}$}} & $23.76 * \star$ & 12.08 \\
\hline & & $(3.11)$ & $(1.34)$ \\
\hline \multicolumn{2}{|l|}{ Constant } & Yes & Yes \\
\hline Year enrl & Yes & Yes & \\
\hline Secondary & Yes & Yes & \\
\hline Faculty & Yes & Yes & \\
\hline Treatment & & Yes & Yes \\
\hline MatrC $\times$ Period & & Yes & Yes \\
\hline Identifier & & & Yes \\
\hline $\mathrm{R}^{2}$ & 0.472 & 0.502 & $\begin{array}{c}0.829 \\
0.0----1\end{array}$ \\
\hline
\end{tabular}




\section{Conclusions}

In this paper we account for a lab experiment where 95 subjects were confronted with the choice of their preferred extent of income redistribution, when different transition matrices stochastically assigned incomes over different time horizons. We find that the preferred taxation declines when the transition matrices are characterised by prospect of upward mobility (i.e. individual below average income have an above average expected income for the next period). This result is robust against alternative specifications, accounting for individual factors (such as inequality and/or risk aversion) and framing effects. It holds even when we introduce individual fixed effects accounting for individual unobservables. Thus our results support the theoretical predictions of the POUM hypothesis proposed by Benabou and Ok (2001a), showing that under specific transition matrices the support to redistribution is reduced in the vicinity of average income. Also in line with theoretical predictions, we find that longer time horizons call for reduced taxation, because individuals appreciate the freedom of changing the optimal tax when confronted with different incomes in the future. These results hold even when controlling for risk aversion, that on theoretical grounds represent a confounding factor.

In our opinion, the main limit of the present research is the imperfect measures of fairness and risk aversion. However, using fixed effect controls takes care, on econometric grounds, of all these unobservable. We have also avoided to frame social interactions in tax selection, which probably dominates the optimal selection of tax rate in many contexts (for example where tax avoidance is made available to the subjects). This constitutes our next research issue. 


\section{Appendix A. Instructions provided before the experiment started}

"Points" are the currency during the experiment, with an exchange rate of 300 points $=1$ euro.

There are two main concepts behind the experiment.

\section{1) TAXATION}

During the experiment you have to choose a tax rate to be applied to your income. This choice will be repeated several times under different rules and conditions.

The choice of every participant affects his/her income only. In a parallel manner, one's income is not affected by the choices of other participants.

In every repetition of the game, you will be assigned an income from three possible levels. You will be asked to choose a tax rate to be applied to that income (in some cases after but usually before knowing it) to determine your earnings in that repetition.

Your earnings in every repetition of the experiment depends upon two factors:

1) the income level that is assigned to you;

2) the tax rate that you choose.

What does taxation imply? A tax rate $t$

a) determines a decrease of incomes above the average. In particular, a fraction $\boldsymbol{t}$ of the income above the average is collected;

b) determines an increase of incomes below the average. In particular, it provides a subsidy equal to a fraction $\boldsymbol{t}$ of the difference between the average income and the income that has been assigned.

For instance, if there are three income levels $(10,20,42)$ and the average income is 24 , the effect of a tax rate equal to $\mathbf{2 5 \%}$ is as follows:

income $=10$ : taxation determines a subsidy equal to the $25 \%$ of (24-10), i.e. $3.5 \quad$ income after taxation $=13.5$

income $=20$ : taxation determines a subsidy equal to the $25 \%$ of $(24-10)$, i.e. $1 \quad$ income after taxation $=21$

income $=42$ : taxation determines a contribution equal to the $25 \%$ of $(42-24)$, i.e. 4.5 income after taxation $=37.5$

Roughly speaking, taxation redistributes income from the rich individuals to the poor ones, where rich and poor in this context mean with an income above and below the average, respectively.

\section{2) The TRANSITION MATRIX}

The transition matrix is a table that summarizes which probability every participant has to reach a given level of income given a starting level of income

\begin{tabular}{|c|c|c|c|}
\hline & To 10 & To 20 & To 42 \\
\hline From 10 & $60 \%$ & $30 \%$ & $10 \%$ \\
\hline From 20 & $30 \%$ & $30 \%$ & $40 \%$ \\
\hline From 42 & $10 \%$ & $40 \%$ & $50 \%$ \\
\hline
\end{tabular}

For instance, let's focus on an individual whose starting income is 10 . In the following period, his/her income will stay equal to 10 in the $60 \%$ of the cases, it will be equal to 20 in the $30 \%$ of the cases and it will be equal to 42 in the remaining $10 \%$ of the cases. If his/her income in the next period will actually be equal to 42 , in the subsequent period his/her income will be equal to10 in the $10 \%$ of the cases, it will be equal to 20 in the $40 \%$ of the cases and it will stay equal to 42 in the remaining $50 \%$ of the cases. The process can be iterated even further in a similar manner.

NB: The transition matrix always refers to INCOMES BEFORE TAXATION. In other words, the matrix refers to gross incomes. 


\section{Appendix B.}

Instructions concerning the simulator (displayed during the experiment)

The SIMULATOR. The goal of the simulator it to make you familiar with the structure of the game, but it does not directly affect your earnings. You have the possibility to introduce three mock tax rates. The simulator will compute your expected income for next period(s) based on the probabilities displayed by the transition matrix and according to your starting income. This expected income will be modified (deducting taxes if above the average and adding subsidies if below the average) according to each of the mock tax rates you introduced. 


\section{References}

Alesina, A. and E.La Ferrara 2002, Preferences for redistribution in the land of opportunities, mimeo.

Amiel, Y. and F.A. Cowell (1999). Thinking about Inequality, Cambridge University Press, Cambridge.

Benabou, R. and E.Ok. 2001a. Social Mobility and the Demand for Redistribution: The POUM Hypothesis". Quarterly Journal of Economics, 116(2): 447-487.

Benabou, R. and E.Ok. 2001b. Mobility as progressivity: ranking income processes according to equality of opportunity. NBER wp.8431.

Corneo, G. and H.P.Grüner. 2000. Social limits to redistribution. American Economic Review 90(3): 14911507.

Corneo, G. and H.P.Grüner. 2002. Individual preferences for political redistribution. Journal of Public Economics 83: 83-107.

Cowell, F.A. and E. Schokkaert (2001). Risk perceptions and distributional judgements, European Economic Review, 45: 941-52.

Fong, C. 2001. Social Preferences, Self-Interest and the Demand for Redistribution, Journal of Public Economics, 82: 225-246.

Fischbacher, U. 2002. zTree Experimenter's Manual. University of Zurich, mimeo.

Meltzer, A. and S. Richards 1981. A Rational Theory of the Size of Government. Journal of Political Economy, 89: 914-27.

Palacio-Huerta, I., Serrano, R. and O. Volij 2001. Rejecting Small Gambles Under Expected Utility: A Comment on Rabin. WP 2001-05, Department of Economics, Brown University.

Piketty, T. 1995. Social mobility and redistributive politics. Quarterly Journal of Economics 110(3): 551-584.

Rabin, M. 2000. Risk Aversion and Expected-Utility: A Calibration Theorem. Econometrica, 68, 12811292.

Ravallion, M. and M.Lokshin. 2000. Who wants to redistribute? The tunnel effect in 1990s Russia. Journal of Public Economics 76: 87-104. 